\title{
Using children's drawings as data in child-centred research
}

\author{
Brian Merriman \& Suzanne Guerin \\ UCD School of Psychology, University College Dublin, Ireland
}

\begin{abstract}
Child-centred research shows a respect for children and promotes their entitlement to be considered as persons of value and persons with rights. With the growing interest in this approach to psychological research, researchers are using new methods to help them access children's perspectives. While drawings have been in use throughout the history of developmental psychology, they have more often been used as projective tests than as tools to access the views of children. This paper examines the use of drawings as data in child-centred psychological research, focusing on the benefits of this method and issues of data analysis, with reference to some of the existing literature in this area. The example at the heart of this paper explores the career aspirations of 151 Street Children from Kolkata (Calcutta), India, by asking them to draw a picture of 'the sort of person you want to be when you grow up'. This method allowed the participation of children who are not literate, and was also seen as an unintimidating and even enjoyable activity for the children involved. Conclusions will be drawn around the potential and actual contribution of drawings to child-centred research.
\end{abstract}

Children's drawings have been of interest to psychologists for over a century (Sully, 1896). Drawings have since been used as indicators of developmental level (Costall, 1997; Goulomb, 2002; Koppitz, 1968; Lowenfeld \& Brittain, 1967), IQ (Aikman, Belter \& Finch, 1992), and attachment (Madigan, Ladd \& Goldberg, 2003). They have also been used for self-description (Stiles, Gibbons, Lie, Sand \& Krull, 1998), as tools in clinical assessment and treatment (Rubin, 1984; Veltman \& Browne, 2001), and as a research tool (Stiles, Gibbons \& Schnellman, 1987). The range of uses of drawings in research highlights their complexity and flexibility such that they can be used as tools for facilitating communication or to aid assessment in their own right (Burkitt, 2004). We are mainly concerned, however, with drawings as a method of data collection and will only briefly examine their other uses in psychology.

\section{Using drawings in psychology}

Despite our focus on drawings as a method of data collection, it is valuable to consider why they have been used in psychology and the advantages of the approach. For readers with an interest in the conceptual issues, Thomas and Jolley (1998) present a thorough review. Of more interest to the present paper are the practical advantages of using drawings. These include: the popularity of the activity among children (Thomas \& Jolley, 1998); its typical perception as fun and non-threatening, unlike most testing situations (Rubin, 1984); and the fact that it does not require literacy and verbal skills (DiCarlo, Gibbons, Kaminsky, Wright \& Stiles, 2000). In research, drawings lend themselves to cross-cultural comparisons because they can avoid some of the difficulties of translation (Stiles \& Gibbons, 2000). Moreover, DiCarlo et al. (2000) write that the failure of standardised tests to reveal the strengths and resourcefulness of Street Children prompted them to look for alternative ways to conduct research with this group. In clinical settings, drawings are used as focused activity to engage the child's interest, to put at ease, to provide opportunities for questions and observation in 
clinical assessment (Thomas \& Jolley, 1998).

Our foremost rationale for the use of drawing is that it is a child-centred method. Childcentred research shows a respect for and promotes the entitlement of children to be considered as persons of value and persons with rights (Greene \& Hill, 2005). It has its roots in humanistic philosophy and psychology as it emerged in the 1960s and 1970s, and children were one of the marginalised groups whose voices were heard, along with those of women and ethnic minorities (Greene \& Hill, 2005). If you want to know what a person thinks about something, ask them. They may tell you (after Kelly as cited in Bannister \& Fransella, 1971). DiCarlo et al.'s (2000) work is thus child centred in that they used interviews and drawings. These provide the opportunity for children to express themselves and their views as well as for positive interactions between service providers and children. The pictures that result, they add, 'provide rich information concerning the children's social circumstances, values and aspirations' (DiCarlo et al., 2000, p. 114).

Making sense of drawings: Issues of analysis There are a number of issues in the use of drawings in general and of methods of analysis in particular which must be addressed. The first has to do with the use and interpretation of drawings in a clinical setting. It has been argued that children's drawings may just be reproductions according to pictorial conventions and cultural rules (Burkitt, 2004). We may learn little more than those conventions from their drawings, and even then may misinterpret them. Thomas and Jolley (1998), for example, suggest that it is a mistake to assume that all children (but especially younger ones) have as their goal in drawing a visually realistic depiction of their chosen subject matter' (p. 130). They further question the value of drawings in clinical practice, pointing out that severe problems of reliability arise when we turn to the interpretation of features by clinicians. In this regard, interpretation of drawings may be no different from other projective tests (Thomas \& Jolley, 1998) and there is still little empirical support in clinical samples that drawings reveal either the child's personality or emotional state (Jolley \& Vulic-Prtoric, 2001). Thomas and Jolley (1998) explain that children's drawings on their own are too complexly determined and inherently ambiguous to be reliable sole indicators of the emotional experiences of the children who drew them. The problem for making a reliable interpretation of the significance of a drawing is that a given feature could plausibly support several different interpretations, depending on which of many possible processes was active or dominant in the production of the drawing, and on the person interpreting the drawing. Rubin (1984), for instance, recalls:

A child psychologist once scoffed at the notion proposed by some that the children at Bellevue painted boats on the water because it symbolised the separation from their mothers, making the point with some scorn that they drew boats because the hospital was on the East River and that was all they saw! (p. 45).

A number of the systems of interpretation will be considered next. The study in the example below is an attempt to address these criticisms of over-interpretation of emotion by incorporating systematic, statistically-based content analysis in a more functional interpretation.

There are two distinct ways of approaching the analysis of children's drawings: one which is broadly projective, and another which focuses on content and not on interpretation. The present paper focuses on the latter but for an understanding of its origins we will first briefly outline the former. The projective approach treats drawings as data which must be interpreted by the researcher. One of the most widely used methods for interpreting children's drawings was proposed by Koppitz (1968). From the Human Figure Drawing (HFD) test, Koppitz (1968) derived a projective scoring system for developmental level, emotional indicators, clinical interpretation, and children's attitudes towards their family. Koppitz found that developmental items occur on relatively few HFDs of younger children and increase relative to age. For example, inclusion of the pupil of the eye is 'exceptional' for five-year-old boys but 'common' for twelve-year-olds (pp. 12-13). 
Normative data by age and gender are given. Emotional indicators include emphasised features and omissions that occur on fewer than $15 \%$ of children's drawings at a given age level. Clinical inferences based on these emotional indicators include unconscious needs and conflicts, personality traits, 'approach toward life's problems' (p. 81), and 'attitudes toward themselves' (p. 93). Cox's (1993) work on children's drawings of the human figure, Machover's (1949) work on personality projection, Buck's (1948) House-Tree-Person test, and Burns and Kaufman's (1970) Kinetic Family Drawing test are all in a similar vein and, while it is not suggested that they are identical, there is insufficient scope to consider each in detail. These last three are considered at greater length by Thomas and Jolley (1998) and they conclude that a child's drawing is regarded as 'a conscious or unconscious symbol either for the drawer's experience of the topic depicted, or for some desired outcome involving that topic' (p. 131).

One of the most frequently considered aspects of a drawing is the inclusion or omission of an important feature, or its exaggeration or minimisation with respect to the rest of the drawing (Thomas \& Jolley, 1998). An example of how this method can be applied is given by Jolley and Vulic-Prtoric (2001). They wrote on Croatian children's experience of war and used social scaling as well as the size and placement of emotive topics (e.g., Croatian and enemy soldiers) as indicators of their importance. Social scaling is the relative size of figures and objects according to their perceived social position or importance. This dimension was also used in Aronsson and Andersson's (1996) study of differences in social scaling in the classroom between children in Sweden and Ethiopia. They found that the relative sizes of teachers and pupils in their drawings reflected the respective social scales and that indicators of modernity, such as light bulbs or water taps, were also often largely oversized in their rural Ethiopian settings (Aronsson \& Andersson, 1996). Rudenberg, Janssen and Fridjhon (2001) conducted a similar study of children in South Africa and Northern Ireland looking at their adjustment to violence. This work on emotion and social scaling is prone to the problems of over-interpretation as discussed above.

The recent growth of the second, contentfocused method of analysis has seen the use of drawing as a research tool in areas beyond the measurement of developmental level and clinical assessment, as described in relation to projective methods above. A report by Linesch (2002) on children's spontaneous drawings shortly after the terrorist attacks of 11 September 2001 suggests that, despite being told that the children were 'unaware' of the political climate, the content of the art that emerged reflected the extent of their knowledge of the events: many drew buildings on fire, others drew planes flying towards towers, and one added the words: 'Oh my gosh'.

Content analysis has typically been seen as a quantitative method of analysis, with early definitions focusing on the quantification of text (e.g., Berelson, 1954; Kaplan, 1943). However, Silverman (2001) describes it as a system that can explore both quantitative elements (e.g., counts and frequencies) as well as qualitative patterns (e.g., exploring themes) within text. In addition, Franzosi (2004) refers to its application to images. Taking Hosti's (1969) definition, which described the approach as a 'technique for making inferences by objectively and systematically identifying specific characteristics of messages' (p. 14), it is clear that content analysis has an important contribution to make to the analysis of drawings. It allows both a qualitative exploration of what is drawn, as well as the potential for quantitatively considering how often particular themes or categories appear, and whether these patterns differ based on other factors such as gender, age, etc. In addition, the focus of content analysis on interrater or inter-coder reliability (Franzosi, 2004) allows researchers to apply more credibility checks than other forms of qualitative analysis may typically employ.

One particularly common form of drawing analysis which combines qualitative and quantitative approaches is the system developed by Stiles and Gibbon (2000). This method of analysis was first employed to examine aspects of development. Their work has concentrated 
on adolescents and on their drawings of themselves and of the ideal man or woman. This is based on the assumption that important changes in cognitive processes, peer relationships, appearance and self-concept take place in early adolescence and that one of the most important of these is the capacity to construct ideals (see Stiles \& Gibbon, 2000). The approach combines Koppitz's (1968) emotional indicators with content analysis of the drawings and the comments that accompany them (Kuebli, Stiles, Shebloski \& Gibbons, 1998). With this amalgamation of methods, the Stiles and Gibbons (2000) system provides a more elaborate analysis of children's drawings than more projective methods and a wider window into their cultural influences as seen from their own perspective than that given by more traditional methods such as surveys.

An example of this combination of projective and content-based methods can be seen in DiCarlo et al.'s (2000) study with Street Children in Honduras, which asked participants to draw a picture of the ideal man or woman. However, it was more concerned with the projective aspects of the Street Children's drawings than with the characteristics of the persons drawn or the aspirations depicted. The impact of this study is in the child-centred approach which, as mentioned above, acknowledges the strength and resourcefulness of the children. The Stiles and Gibbons (2000) coding frame, they found, provided 'a more elaborate content analysis of children's drawings and a window into their cultural influences ... as seen from their perspective' (pp. 118-119).

For researchers, drawings are a challenging medium through which to conduct research. The processes of data collection and coding are time-consuming, though the standardised approaches mentioned above and the depth of work with content analysis facilitate the coding process. It is worth restating, then, why drawings are used at all and why these efforts are worthwhile: research using drawings is child centred. In order to elucidate these benefits, it will be useful to look at an application in one particular area, namely children's personal and career aspirations.

\section{Application: Children's career aspirations}

Researchers have long been interested in the type of people children want to be like and the careers they want to pursue (for a review, see Teigen, Normann, Bjørkheim \& Helland, 2000), and the most common methodology employed in these studies is structured questionnaires (e.g., Gash \& Conway, 1997; Kelly, 1989; Lee, 1984; Marjoribanks, 1984, 1985; Simmons \& Wade, 1985). However, Baker, Panter-Brick and Todd (1996) state that this approach has shortcomings, such as the authoritative stance of the researcher, the inappropriateness of questions to children's experiences, and the susceptibility of the method to children's manipulation of the information. One alternative to this approach which is not subject to some of these shortcomings is the use of drawings. The potential to combine research into children's ideals with drawing as a research tool was first explored by Stiles et al. (1998) and in DiCarlo et al.'s (2000) investigation of the aspirations of Street Children in Honduras.

The study detailed in the next part of this article uses drawings in a way that builds on DiCarlo et al.'s (2000) child-centred approach to work with Street Children, Stiles and Gibbons's (2000) analysis, and Kelly's (1989) study of the development of career preferences. It is concerned with the Street Children of Kolkata (Calcutta), India. It looks explicitly at career aspirations but is designed in such a way as to allow participants to express ideals about personal attributes, broad contributions to society or, indeed, anything else they deem valuable in the sort of person they want to be when they grow up. A unique coding frame for analysis of the drawings was devised based on previous research and on what emerged from the drawings themselves.

\section{An Example: The Career Aspirations of Children in Kolkata}

A recent study by Merriman (2004) used drawings to explore the career aspirations of children living 'on' and 'off the street' (i.e., in the care of religious institutions) in Kolkata. Data were collected from participants in two groups: orphaned children in urban residential schools and Street Children in an educational 
programme. The latter project takes in orphaned Street Children currently living on the street with a view to bringing them into mainstream education. The 151 participants in this study included 85 girls (56.3\%) and 66 boys $(43.7 \%)$. They ranged in age from eight to fifteen years $(M=11.34, S D=1.4)$.

Written consent was obtained from the directors of the orphanages and the education programme, who would be considered the legal guardians of the children in their care. In addition, the children were invited to take part and the voluntary nature of participation was stressed. No child declined to take part. Participants were asked the following questions: (a) draw a picture of the sort of person you would like to be when you grow up; (b) draw them doing something; and (c) write a little about who the person is, what they are like, and why you chose them. These instructions were presented in English on the research material, a sheet of A4 paper. The study was introduced by the first author in English, the first language of the organisations, and the instructions were translated into Bangla (Bengali) by a staff member for the benefit of some of the younger participants where necessary. A variety of coloured pencils and crayons (provided by the organisations) were available to all participants. Up to one hour was allowed and completion time was not considered in the analysis.

The study took place in two settings. The first setting was two urban residential schools: one for boys and one for girls. The participants ranged in educational level from Class I to Class VI (comparable to $1^{\text {st }}$ to $6^{\text {th }}$ Class primary in Ireland). Participants were seated at individual desks. The second setting was the Education Programme for Street Children. Children on this programme come from night shelters run by non-governmental organisations (NGOs), from the streets, or are resident in the orphanage but do not yet attend schools. While this group cannot be classified in terms of their educational level, they ranged in age from eight to fifteen years. The programme is run in a large, airy room brightly decorated by the children which is at the top of the building. Almost all who were present participated, working on the floor. Senior students from the school who help tutor the children were present and assisted in monitoring the participants. Some participants spoke little or no English and some were illiterate so these senior students translated or transcribed the comments as necessary. They were instructed only to assist and not to influence the process.

A content analysis was conducted whereby the data were examined for recurring themes. These were combined with selected themes from the Stiles and Gibbons (2000) system of drawing analysis to develop the coding frame used in the present study. The drawings were examined for the socio-economic status (SES) of the occupation (adapted from Kelly, 1989), the required educational level and whether or not it was a Vocational Role. The occupations considered Vocational were priest, brother (religious order), teacher, nurse, doctor, poor helper, and mother. Using content analysis it was also possible to examine the nature of the role depicted, including whether Adult Responsibilities, Work, Leisure, or Homemaking were shown, and whether the role depicted was gender stereotyped. In addition, the drawings were coded based on Contribution to Society (i.e., Helping, Defence, Commerce and Vocation) and Patriotism, Religion, or Achievement Orientation. Once the coding system had been developed, it was applied to the drawings. On completion of coding an interrater reliability test was conducted on a random sample of $10 \%$ of drawings, generated by www.random.org (Haahr, 1998), using the same coding frame and Cohen's kappa coefficients were calculated for each theme. The minimum accepted kappa coefficient of 0.7 was reached on all themes.

The participants drew 22 different occupations, ranging from bank managers to bus drivers, priests to police officers, surgeons to singers (see Figure 1). One notable finding was the number of occupations drawn, which were more than have been elicited in a closed questionnaire (e.g., Kelly, 1989). Combining the content analysis with a frequency analysis, it was found that the most common occupations were teachers (31.8\%) and doctors (19.2\%).

In considering SES, required educational level, and whether or not the occupation drawn 

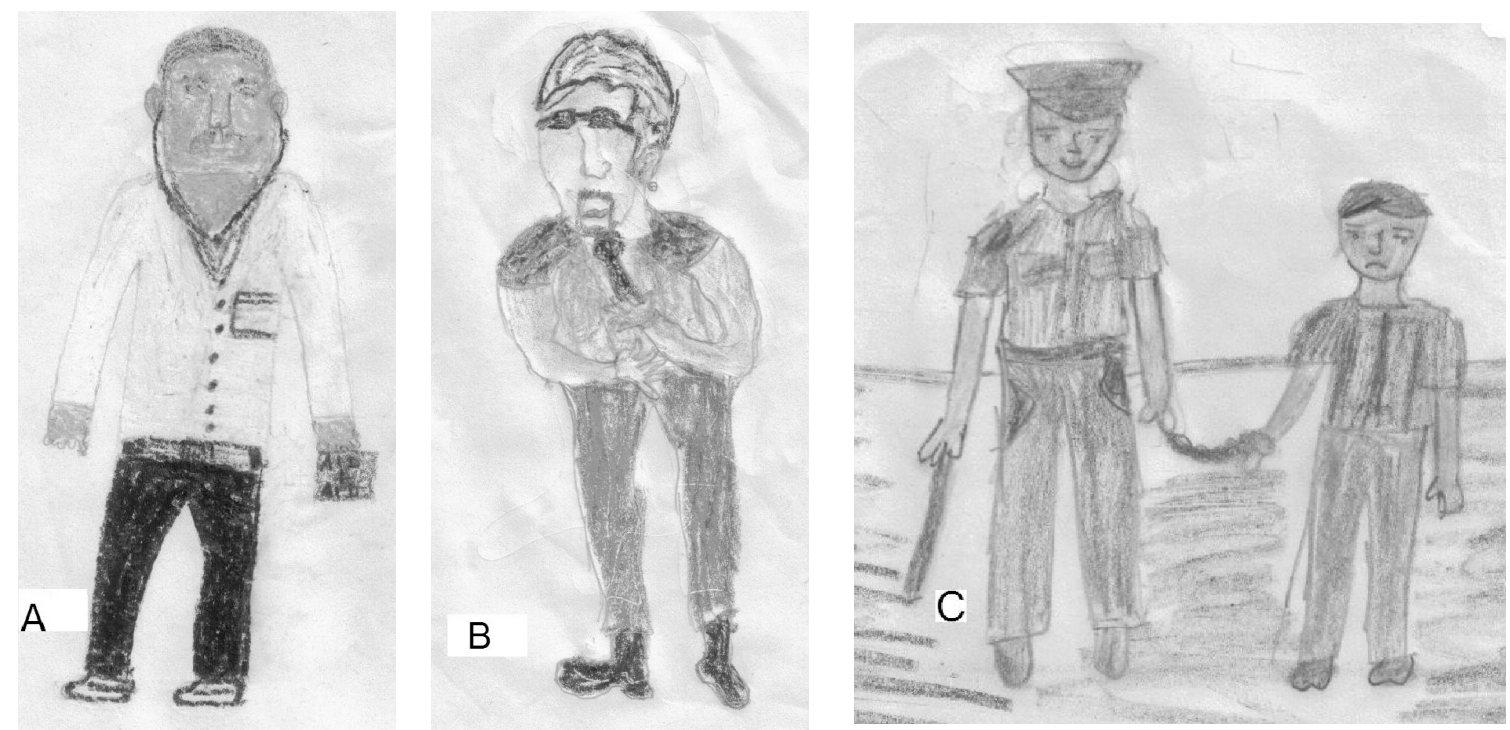

Figure 1(A) Doctor by 9-year-old boy, (B) singer by 11-year-old boy, and (C) police by 11-year-old girl

was a Vocational Role, there was a predominance of White Collar and Professional occupations (39.9\% and $28.7 \%$ respectively) with a requirement for third-level education (67.6\%).

The figures below show examples of different levels of SES. Figure 2A, a drawing by an 11-year-old boy, shows a doctor in an operating theatre. This was coded as Professional, requiring third-level education. Doctor was considered a Vocation Role and these occurred in $60 \%$ of drawings. The second drawing presented (see Figure 2B), by another 11-year-old boy, is of a bus with the boy himself as the driver, representing a Skilled Manual occupation requiring no specific training or education. While it is not exactly intuitive that driving a bus does not require any training, local knowledge was applied in reaching this conclusion.

In considering the nature of the occupation drawn, a number of patterns emerged which highlighted the usefulness of this method. Overall, $67.6 \%$ of the roles depicted were classed as 'not gender specific', as they were judged not to fit traditional male or female stereotyped occupations, while a majority showed adult responsibilities and work. Figure $3 \mathrm{~A}$ shows a teacher by an 11-year-old boy. Teacher was coded as not gender specific owing to the number of male teachers in the girls' school and

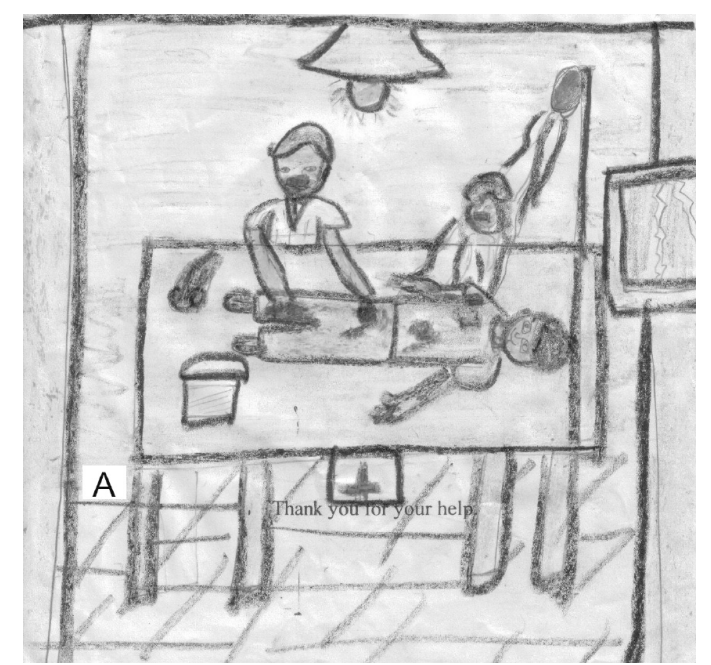

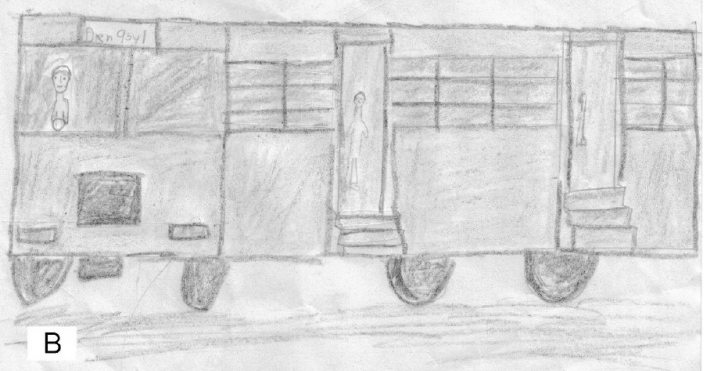

Figure 2(A) Doctor by an 11-year-old boy and (B) bus driver by an 11-year-old boy 

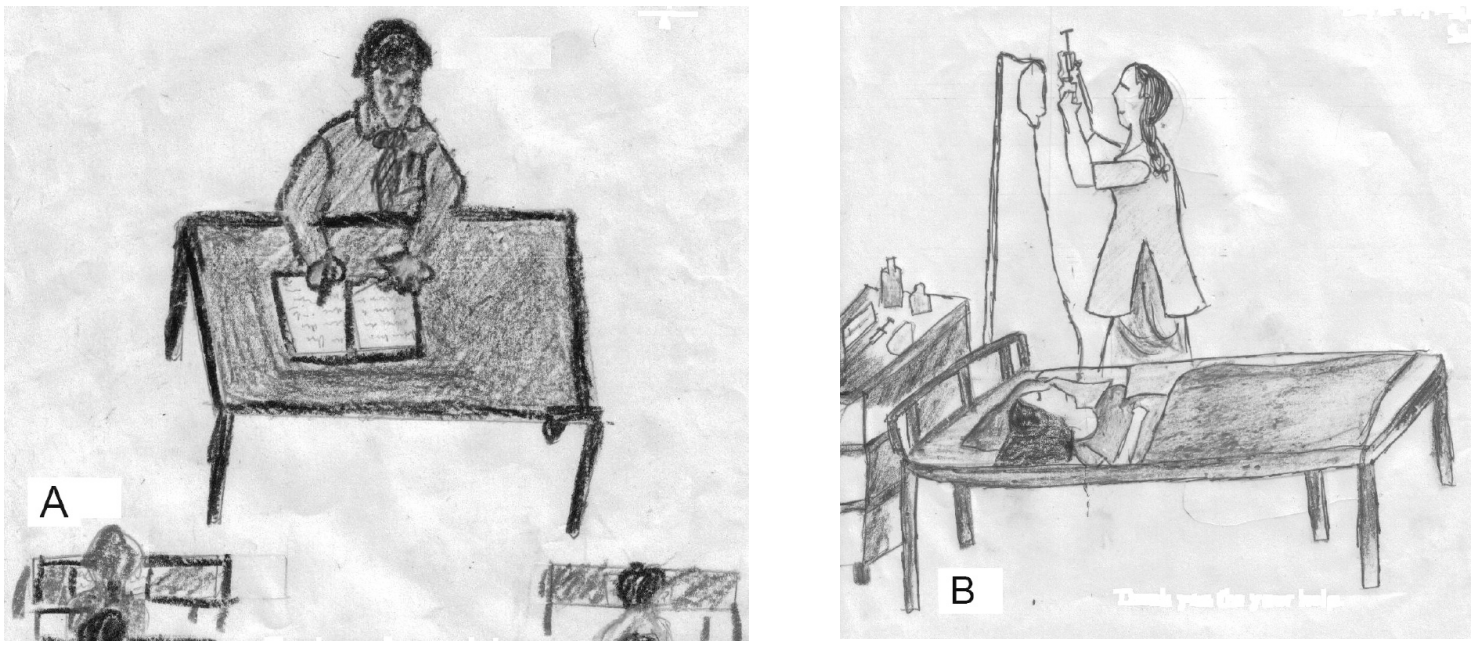

Figure $3(A)$ Teacher by 11-year-old boy and (B) doctor by 11-year-old girl

the presence of teaching brothers in the boys' one. Since teachers were drawn by $31.8 \%$ of participants, this may go some way to account for the high proportion of not gender specific occupations. Figure 3B is a doctor by a 12-yearold girl. The only computer engineers and lawyers were also drawn by girls.

It was also possible to identify some of the values that the participants saw as important. A large majority of the participants (89.4\%) depicted some Contribution to Society, whether Helping, Defence, Commerce, or Others, which included any mention of social advancement or scientific advancement. Figures 1A, 1B, 2A, 3A, $3 \mathrm{~B}$ above and $4 \mathrm{~A}$ below were coded as Helping. Figure 2B was coded as Other and Figure $4 \mathrm{~B}$ as Defence. Figure $1 \mathrm{~B}$, a singer, was coded as depicting Helping as a Contribution to Society, while not immediately obvious because the comments included: 'When I will grow up I want to be a singer because I want to help the people to learn singing.' This perfectly illustrates the value that comments have in addition to the drawings.

Less frequently drawn values (but drawn nonetheless) were Patriotism (depicted by
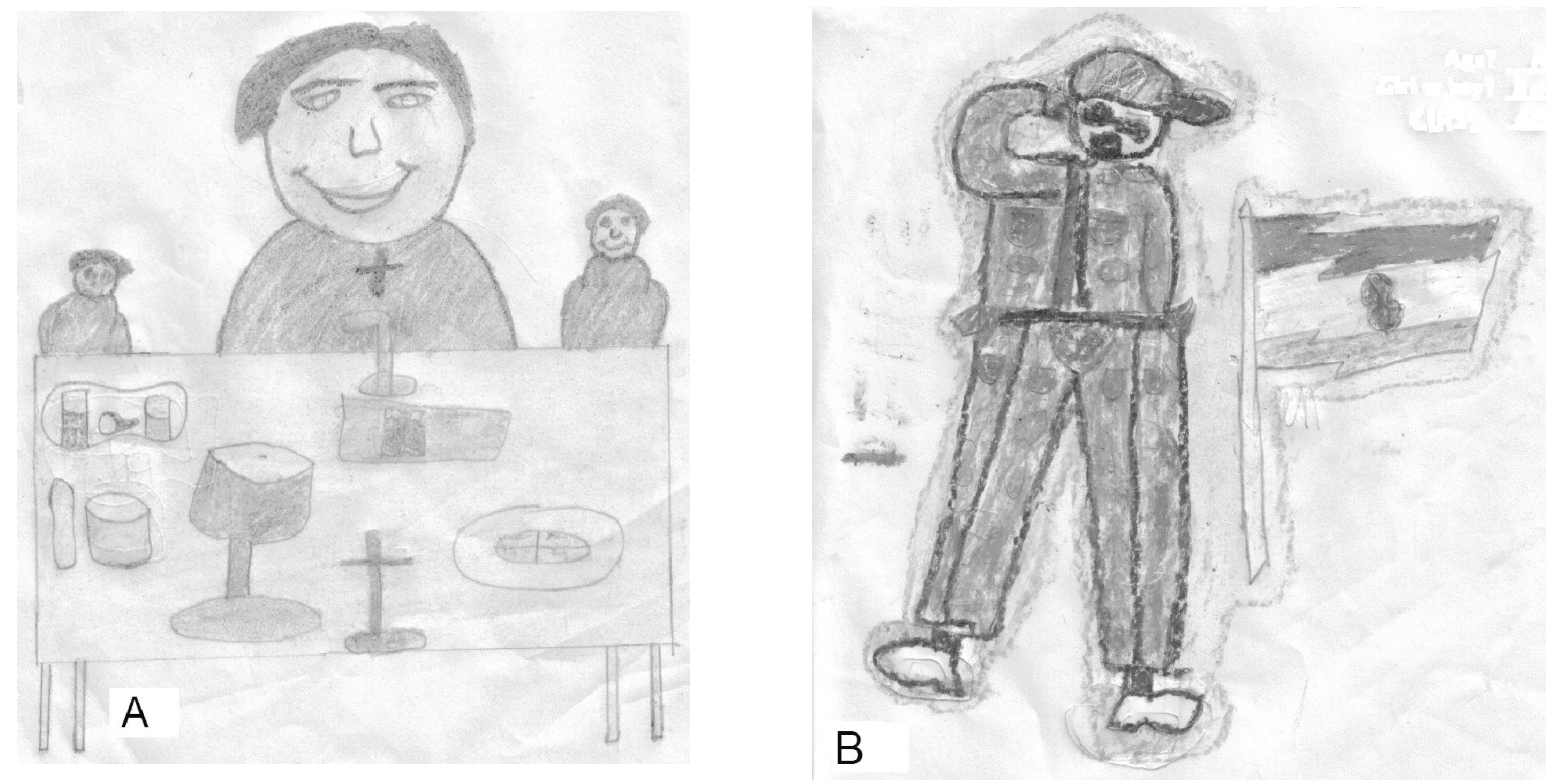

Figure 4 (A) Priest by 13-year-old (B) Military by an 11-year-old boy 
13.3\%), Religion (depicted by $4.7 \%$ ), and Achievement (depicted by 14\%). Patriotic and religious elements were mainly flags and crucifixes. The examples below are a priest (Figure 4A) and a 'military boy' (Figure 4B). The military was coded in a separate SES category for Police and Military since these did not feature as strongly in Kelly's (1989) study.

There are a number of points to be made about this study and the insights gained from it in relation to the use of drawings as a method. The use of drawings helped to overcome other barriers attributable to the setting, particularly linguistic ones. In contrast to questionnaires, the drawings used in the present study required minimal instruction and explanation, avoided some of the problems of translation, and allowed children with limited literacy skills to participate. Secondly, the reliability of the analysis is supported by the use of inter-rater reliability and high levels of agreement.

Another benefit of this method is the flexibility of the analysis of drawings. This study carried out a frequency analysis and this allowed for the statistical comparison of males and females as well as children living on and off the streets. While not reported in this paper, some differences were identified, which provided further insight into the nature of this group's career aspirations. Therefore, the drawings were analysed at both a qualitative and quantitative level, with both descriptive and statistical analyses.

The successful use of drawings as data in this study suggests their value for future research, whether in ideals and aspirations or other areas. The method proved easy to implement and to code, while retaining integrity and validity. The flexibility of the coding frame allowed themes to emerge from the data which would not necessarily have been considered by the researcher. Furthermore, it also proved nonintrusive and even enjoyable for the participants.

\section{CONCLUSIONS}

The above example shows a number of the benefits of using drawings in child-centred research. First, they allow cross-cultural research to be conducted in a way that other approaches, such as questionnaires, could not have. Secondly, they are flexible enough to facilitate the broad variation that emerged in the example described. Thirdly, the benefits of qualitative and quantitative coding and analysis are combined in a way that maintains strong inter-rater reliability. Finally, given the breadth and depth of the results that can emerge, studies using this method can inform both practitioners who work with children and researchers who are trying to understand their lives. We must finally consider why this approach works on three levels: why it works for this sample, why for this topic, and why it works as a childcentred approach in general.

This sample consisted largely of children who are not literate from underprivileged, even impoverished backgrounds. That the method employed did not require high literacy skills and was unthreatening and even fun suited the participants and allowed a rare insight into their lives and thoughts. The volume of data gathered with the ease and lack of intrusion that this method allowed are two of the successes of the above study.

In considering the benefits for researching this topic, it has been noted that this area has most often been investigated with questionnaires and interviews. Questionnaires are often chosen for their convenience, though they can be restrictive: closed questions limit answers and written language limits access to populations with limited literacy skills. Openended questions allow broader scope but content analysis on these crosses into the realm of the qualitative and is closer to interviews. Interviews combine a broad potential range of enquiry with the flexibility to respond to the participant's input. They are time-consuming and so usually limited to small samples. They may not be ideal for children as the process can be intimidating, the questions inappropriate, and the information manipulated by the children (Baker et al., 1996). In cross-cultural research they are subject to translation and in any event the interpretation of transcripts is an issue. Drawings can give a similarly broad range of enquiry but with some of the administrative advantages of questionnaires, specifically facilitating larger samples. The same concerns of over-interpretation apply as with interviews 
and can similarly be addressed with a valid and reliable coding frame. Furthermore, the accompanying comments give clarification of the participant's intent in the same way that questions of clarification can be asked in interviews. As discussed above, drawings are also suitable for cross-cultural research and in child-centred research. Indeed, the contribution of this method to child-centred research is central to this article and, given the context of the special issue, it is here that we must conclude our argument.

Child-centred research implies a respect for children as persons with all the status, rights and responsibilities that follow. This respect entails an openness to the use of methods that are suited to children's level of understanding, knowledge, interests and particular location in the social world (Greene \& Hill, 2005). Using a medium with which they are familiar and comfortable, by not imposing any kind of structure or expectation, and by listening to what children have to say - in this case, seeing what they have to draw - grants precedence to children's experience and respect to their personhood. Drawing, then, offers another tool and another methodological option in childcentred research (for others, see Greene \& Hill, 2005). By being thus better informed as to the views of children, we put ourselves in a better position to address their needs. A creative, pragmatic approach like drawing can be used to review old questions and to explore new questions, the only limits being the creativity and the imagination of the researcher.

\section{REFERENCES}

Aikman, K.G., Belter, R.W. \& Finch, A.J., Jr. (1992). Human figure drawings: Validity in assessing intellectual level and academic achievement. Journal of Clinical Psychology, 48, 114-120.

Aronsson, K. \& Andersson, S. (1996). Social scaling in children's drawings of classroom life: A cultural comparative analysis of social scaling in Africa and Sweden. British Journal of Developmental Psychology, 14, 301-314.

Baker, R., Panter-Brick, C. \& Todd, A. (1996). Methods used in research with street children in Nepal. Childhood: A Global
Journal of Child Research, 3, 171-193.

Bannister, D. \& Fransella, F. (1971). Inquiring man: The theory of personal constructs. Harmondsworth: Penguin.

Berelson, B. (1954). Content analysis. In G. Lindzey (Ed.), Handbook of social psychology: Vol. 1 (pp. 488-522). Reading, MA: AddisonWesley.

Buck, J.N. (1948). The HTP test. Journal of Clinical Psychology, 4, 151-159.

Burkitt, E. (2004) Drawing conclusions from children's art. The Psychologist, 17, 566-568.

Burns, R.C. \& Kaufman, S.H. (1970). Kinetic Family Drawing (K-F-D). New York: Brunner-Mazel.

Costall, A. (1997). Innocence and corruption: Conflicting images of child art. Human Development, 40, 133-144.

Cox, M.V. (1993). Children's drawings of the human figure. Hove: Lawrence Erlbaum.

DiCarlo, M.A., Gibbons, J.L., Kaminsky, D.C., Wright, J.D. \& Stiles, D.A. (2000). Street children's drawings: Windows into their life circumstances and aspirations. International Social Work, 43, 107-120.

Franzosi, R. (2004). Content analysis. In M. Lewis-Beck, A. Bryman \& T.F. Liao (Eds.), The Sage encyclopedia of social science research methods: Vol. 1 (pp. 186-189). Thousand Oaks, CA: Sage.

Gash, H. \& Conway, P. (1997). Images of heroes and heroines: How stable? Journal of Applied Developmental Psychology, 18, 349-372.

Goulomb, C. (2002). Child art in context: A cultural and comparative perspective. Washington, DC: APA.

Greene, S. \& Hill, M. (2005). Researching children's experience: Methods and methodological issues. In S. Greene \& D. Hogan (Eds.), Researching children's experience (pp. 1-21). London: Sage.

Haahr, M. (1998) Random.org - True random number service. Retrieved on 1 January 2004 from www.random.org.

Hosti, O.R. (1969). Content analysis for the social sciences and humanities. Reading, MA:Addison-Wesley.

Jolley, R.P. \& Vulic-Prtoric, A. (2001). Croatian children's experience of war is not reflected in the size and placement of emotive topics in 
their drawings. British Journal of Clinical Psychology, 10, 107-110.

Kaplan, A. (1943). Content analysis and the theory of signs. Philosophy of Science, 10, 230-247.

Kelly, A. (1989). 'When I grow up I want to be ...': A longitudinal study of the development of career preferences. British Journal of Guidance and Counselling, 17, 179-200.

Koppitz, E.M. (1968). Psychological evaluation of children's human figure drawings. New York: Grune \& Stratton.

Kuebli, J., Stiles, D.A., Shebloski, B. \& Gibbons, J.L. (1998). Commentary on 'Adolescents in a changing world: Intracultural diversity in developmental contexts'. Cross-Cultural Research: The Journal of Comparative Social Science, 32, 299-311.

Lee, C.C. (1984). An investigation of the psychosocial variables in the occupational aspirations and expectations of rural black and white adolescents: Implications for vocational education. Journal of Research and Development in Education, 17, 28-34.

Linesch, D. (2002). Art therapy students collect children's drawings: Parallel responses to September 11. The Arts in Psychotherapy, 29, 155-157.

Lowenfeld, V. \& Brittain, W.L. (1967). Creative and mental growth ( $4^{\text {th }}$ ed). New York: Macmillan.

Machover, K. (1949). Personality projection in the drawings of the human figure. Springfield, IL: Thomas.

Madigan, S., Ladd, M. \& Goldberg, S. (2003). A picture is worth a thousand words: Children's representations of family as indicators of early attachment. Attachment and Human Development, 5, 19-37.

Marjoribanks, K. (1984). Families, environment, and adolescents' aspirations: A follow-up study. Journal of Educational Research, 77, 166-171.

Marjoribanks, K. (1985). Families, schools, and aspirations: Ethnic group differences. Journal of Experimental Education, 53, 141-147.

Merriman, B. (2004). Drawing ideals: The career aspirations of Kolkatan street children. Unpublished B.A. thesis, School of Psychology, University College Dublin.
Rubin, J.A. (1984) Child art therapy: Understanding and helping children grow through art (2nd ed.). New York: Van Nostrand Reinhold.

Rudenberg, S.L, Janssen, P. \& Fridjhon, P. (2001). Living and coping with ongoing violence: A cross-national analysis of children's drawings using structured rating indices. Childhood: A Global Journal of Child Development, 8, 31-55.

Silverman, D. (2001). Interpreting qualitative data: Methods for analysing talk, text and interaction. London: Sage.

Simmons, C.V. \& Wade, W.B. (1985). A comparative study of young people's ideals in five countries. Adolescence, 20, 889-898.

Stiles, D.A. \& Gibbons, J.L. (2000). Manual for evaluating individual and social values expressed in international adolescents' drawings of ideal woman and man. World Cultures, 11, 181-221.

Stiles, D.A., Gibbons, J.L., Lie, S., Sand, T. \& Krull, J. (1998). 'Now I am living in Norway': Immigrant girls describe themselves. CrossCultural Research: The Journal of Comparative Social Science, 32, 279-298.

Stiles, D.A., Gibbons, J.L. \& Schnellman, J. (1987). The smiling sunbather and the chivalrous football player: Young adolescents' images of the ideal women and men. Journal of Early Adolescence, 7, 411427.

Sully, J. (1896). Studies of childhood. London: Longmans Green.

Teigen, K.H., Normann, H.-T.E., Bjørkheim, J.O. \& Helland, S. (2000). Who would you most like to be like? Adolescents' ideals at the beginning and the end of the century. Scandinavian Journal of Educational Research, 44, 5-26.

Thomas, G.V. \& Jolley, R.P. (1998). Drawing conclusions: A re-examination of empirical and conceptual bases for psychological evaluation of children from their drawings. British Journal of Clinical Psychology, 37, 127-139.

Veltman, M.W.M. \& Browne, K.D. (2001). Identifying childhood abuse through favourite kind of day and kinetic family drawings. The Arts in Psychotherapy, 28, 251-9. 